\title{
Las humanidades hoy
}

\author{
Vidaluz Meneses \\ Escritora nicaragüense
}

A los Padres Amando López y Xabier Gorostiaga, S.J. (q.e.p.d.)

Al contribuir con este número conmemorativo de la revista Encuentro de la Universidad Centroamericana, mi Alma Mater, quiero hacerlo aportando algunas reflexiones sobre los desafíos de las humanidades en el actual contexto.

En principio, me quiero referir a los retos de una Facultad de Humanidades, de la cual me correspondió ser Decana en la década de los noventa, período en el que asumí la conducción de lo que pienso fue una primera fase de la reforma académica realizada dentro de la ineludible tensión entre la necesidad de incorporar determinados conocimientos e instrumental pertinentes para abordar e intervenir en la nueva realidad y la sostenibilidad de las carreras, realizada además, ésta, en el período en que fuimos partícipes y presenciamos el desmontaje de un proyecto nacional revolucionario que emocionalmente tuvo repercusiones en el país, y del cual las universidades no estuvieron exentas.

Considerando pues, que el clima traumático posiblemente ha sido superado, pienso que sería saludable un recorrido retrospectivo a la iniciativa de cambio y actualización liderada por el recordado Rector, Xabier Gorostiaga, quien en reiteradas ocasiones nos dijo: "No estamos en una época de cambios sino en un cambio de época" frase que para no pocos significó algo que intuíamos pero aún no comprendíamos a plenitud. Un cambio de época suponía enterarnos cuáles eran los signos que denotaban y anunciaban esa nueva etapa en la que comenzaba a entrar la humanidad. Significaba, como bien nos advertía la PhD Ileana Rodríguez, Catedrática nicaragüense en Ohio University, quien nos asesoró durante un período, que cada una de las y los docentes deberíamos ahora releer nuestras respectivas disciplinas. No se podía continuar con los mismos enfoques y contenidos y esto daba mucho miedo e inseguridad.

Obviamente, cada ser humano vive determinada experiencia de distinta forma y es mi propia vivencia y perspectiva sobre lo acontecido lo que estoy expresando, y de allí parto para situarme en el presente.

La reforma universitaria de los noventa puso en movimiento a todas las Facultades. En la de Humanidades intentamos propiciar lo interdisciplinario y lo transdisciplinario, aspecto que personalmente, viniendo de la experiencia del trabajo cultural en el período revolucionario, había considerado necesario desde que asumí la decanatura de una Facultad con carreras que facilitaban establecer vasos comunicantes, y desde el logrado consenso del Consejo de Facultad, al reconocer que una realidad compleja había que enfrentarla con soluciones complejas. 
Tal como decía el P. Ignacio Martín Baró, S.J., En primer lugar, pienso que debemos buscar o elaborar modelos adecuados para captar y enfrentar la peculiaridad de nuestros problemas. Esto nos exige conocer más de cerca nuestra realidad, la realidad dolorida de nuestro pueblo, que es mucho más pluriforme de lo que asumen nuestros esquemas de trabajo usuales. No se trata de plantear un ingenuo nacionalismo psicológico. De lo que se trata es de volver nuestra mirada científica, es decir, iluminada teóricamente y dirigida en forma sistemática, hacia esa realidad concreta que son los hombres y las mujeres de nuestra sociedad, en el entramado de sus relaciones sociales. Ello nos obliga, por un lado, a examinar nuestros presupuestos teóricos, no tanto desde su racionalidad intrínseca, cuanto desde su racionalidad histórica, es decir, de si sirven y son realmente eficaces en el aquí y el ahora. Pero, por otro lado ello nos obliga a deshacernos del velo de mentira en el que nos movemos y a mirar la verdad de nuestra existencia social sin las andaderas ideológicas del quehacer rutinario o de la inercia profesional.

Se trataba, por ejemplo, de que la carrera de Psicología abandonara o redujera el perfil clínico que tenía y se le imprimiera un sesgo más social y antropológico. Que la conflictiva relación entre Sociología y Trabajo Social se superara mediante el reconocimiento de dimensiones complementarias de ambas carreras: la Sociología, con énfasis en la fase de diagnóstico y el Trabajo Social, en la de intervención. Por su parte, Arte y Letras debía conservar su oferta única en el país sobre las "bellas artes", pero armarla de un instrumental que le permitiese incorporarse al ámbito de las ciencias sociales, aportando al estudio y promoción de la cultura. Paralelo a ello, la Cátedra de Género y Poder debía de adquirir un carácter interdisciplinario y abarcador de todas las carreras de la Universidad.

¿Cómo evolucionó esta reforma después de que nos retiramos una serie de profesores/as, acogidos/as al plan dispuesto administrativamente para tal fin, y en mi caso, finalizado mi período para el que fui electa Decana? No lo sé. Pero dado que posteriormente fue cerrada la carrera de Ciencias de la Cultura; se integró la Escuela de Idiomas y recientemente la Carrera de Ciencias de la Comunicación, eso demuestra que se está cumpliendo lo que la Dra. Mayra Luz Pérez Díaz, entonces Vice-Rectora Académica, expresaba: "Cuando se habla de reforma se piensa en un concepto idílico, inalcanzable o abstracto. La Reforma no es otra cosa que [.....] un intento de replantear la misión de la Universidad a tono con un mundo cambiante", o sea que la reforma continúa, y este hecho me parece de una enorme importancia para los fines y objetivos de la Universidad Centroamericana.

Como una definición de la nueva época que enunciaba Gorostiaga, cito a José De Souza Silva, autor brasileño que nos ha iluminado en los años posteriores y que nos dice: $L a$ génesis del actual cambio de época está fuertemente asociada a tres revoluciones: sociocultural, económica y tecnológica, cuyos impactos cruzados (no necesariamente compatibles entre sí) están cambiando el sistema de ideas, el sistema de técnicas y la institucionalidad de la época histórica del industrialismo.

Dentro del ámbito sociocultural, De Souza ubica a los movimientos feministas, ambientalistas y de derechos humanos, justicia étnica, igualdad social y participación democrática. 
En lo económico, parte de finales de los años 70 cuando surge la crisis del petróleo iniciada por dos choques en los precios de este disputado recurso. Ésta reveló el agotamiento del régimen de acumulación de capital en la época industrial, dando inicio a la formación de un régimen de acumulación de capital (la mayor, jamás vista en la historia de la humanidad, según nos hacía ver Gorostiaga), de naturaleza corporativa, de carácter transnacional, de alcance global y dependiente de un factor intangible: la información.

En lo tecnológico, De Souza fija "a mediados de los años 70, el inicio de una revolución en torno a la tecnología de la información que ha influenciado otras revoluciones científicas y tecnológicas y ha penetrado a la mayoría de los medios de comunicación. La dimensión microelectrónica de esta revolución, -dice- hace posible la concepción de redes virtuales capaces de comprimir y eventualmente desmaterializar el tiempo histórico y el espacio geográfico".

Sería interesante rescatar de los archivos la propuesta de una carrera única de Humanidades trabajada por el joven sacerdote jesuita Juan Carlos Núñez. Pienso que en este ejercicio se propuso integrar lo interdisciplinario y lo transdisciplinario y posiblemente bajar los costos de las carreras fundidas en una sola. Resultado de nuestra gestión fueron ciertos cambios en la curricula de las cuatro carreras, de los cuales, quizá los más significativos fueron los de Artes y Letras que también cambió su nombre al de Ciencias de la Cultura, pero cuyo cierre posterior fue inminente, entiendo que por falta de demanda.

Pero a este cierre le sucedió la incorporación de la Escuela de Idiomas y recientemente la de Ciencias de la Comunicación, por lo que considero que la Facultad vuelve a adquirir un rico potencial de cara al nuevo contexto y por lo tanto se podría promover una dinámica interna que permita la actualización de sus contenidos, el debate constante de su claustro de profesores/as, la actualización permanente de éstos/as, la articulación de todas las carreras con vistas a potenciar su impacto en la realidad mediante el abordamiento de los problemas desde las distintas disciplinas.

Se requiere acompañar el proceso de una comisión idónea que determine el costo del mismo y garantice la sostenibilidad de las carreras renovadas, dándole igual importancia y apoyo a la docencia, a la investigación y a la proyección social, evitando sacrificar el tiempo asignado para la investigación en función de las horas/clase, y evitando lamentables cierres como el de Ciencias de la Cultura y algunos años antes el de Bibliotecología, ésta última de vital importancia por la necesaria puesta en práctica de la nueva Ley de acceso a la información pública. Aplicar esta Ley supone la organización previa de la información.

Finalmente, creo que hay dos grandes déficits en nuestro medio que una universidad cristiana debe contribuir a subsanar:

1. La falta de ética a todos los niveles. En ese sentido, la UCA debe insistir en el fomento de los valores cristianos, en la coherencia de toda la comunidad universitaria para que contribuya a desenmascarar la doble moral, la actitud tramposa, el doble discurso que impera en nuestra sociedad. 
2. Que se tome en cuenta la "realidad dolorida" de nuestro pueblo. Como dice Martín Baró, que si bien se refería a la de El Salvador, la experiencia de la guerra igualmente está presente entre nosotros, en sus consecuencias. Son egresadas/os de la UCA, junto con colegas nacionales e internacionales, quienes han coincidido en el diagnóstico de síndrome de stress post traumático debido a la serie de duelos no procesados del que padecen nuestros compatriotas y que les impide planificar su futuro.

Reitero mi intención expresada al inicio de este escrito reflexivo que es la de aportar fraternamente a una institución bajo el rectorado de una mujer de prestigiada vida académica y a una comunidad universitaria que pueden contribuir con alcanzar metas esperanzadoras que nos conduzcan al alumbramiento de una nueva humanidad. 